\title{
3. EL CONTENIDO ESENCIAL DEL DERECHO DE HUELGA
}

\author{
MARIA LUISA BALAGUER CALLEJÓN
}

Profesora de Derecho Constitucional

Universidad de Málaga 


\section{SUMARIO}

INTRODUCCIÓN.-I. EL CONTENIDO ESENCIAL DEL DERECHO DE HUELGA.-1. Determinación de lo que es el contenido esencial de los Derechos Fundamentales. 2. El contenido esencial del derecho a la huelga en la jurisprudencia del Tribunal Constitucional. II. EL CONTENIDO ESENCIAL DEL DERECHO A LA HUELGA Y LOS SERVICIOS ESENCIALES DE LA COMUNIDAD.-III. CONCLUSIONES.-BIBLIOGRAFIA. 
Revista de Derecho Político, núm. 34, 1991, pp. 123-141

\title{
3. EL CONTENIDO ESENCIAL DEL DERECHO DE HUELGA
}

\author{
POR \\ MARÍA LUISA BALAGUER CALLEJÓN \\ Profesora de Derecho Constitucional \\ Universidad de Málaga
}

INTRODUCCIÓN

Los derechos fundamentales tienen una protección especial, en su regulación y en su aplicación. En su regulación en cuanto a que la Constitución Española impone un límite al legislador, obligando a que en su regulación respete su «contenido esencial», y en su aplicación en cuanto al establecimiento de unas garantías especiales. Esto justifica que «sólo por ley, que en todo caso ha de respetar su contenido esencial» (art. 53 de la $C E)$, se podrán regular estos derechos.

El concepto de "contenido esencial», es pues determinante en la regulación de los Derechos Fundamentales.

$Y$ esta idea de contenido esencial de un derecho, no parece apuntar a cosa distinta que a reservar una esfera, con los aspectos «intrínsecos» del derecho, indisponible para el legislador, y al que éste no puede afectar con la ley. El derecho se debe regular en todos sus aspectos, pero ha de tenerse en cuenta que el legislador no puede penetrar ni invadir aquellos aspectos del derecho que se consideran precisamente en su «contenido esencial».

Si decimos que cada derecho fundamental tiene un contenido esencial, indisponible para el legislador, el contenido esencial es la esencia misma del derecho fundamental. El límite de cada derecho fundamental está justamente ahí, en su contenido esencial.

A la hora de ponderar los derechos y sus posibles colisiones entre unos y otros, ha de tenerse en cuenta este límite, por encima del cual un derecho fundamental no puede ser restringido. La ponderación de derechos 
fundamentales asi entendida, es la relación entre los Derechos Fundamentales desde sus contenidos esenciales en cuanto derechos.

Por ello, es fundamental en el derecho de huelga considerar su contenido esencial, pues a diferencia de otros derechos fundamentales donde la ponderación se efectúa por los tribunales de justicia fundamentalmente, en el derecho de huelga la ponderación, sobre todo en el caso de los servicios públicos, se hace por la Administración Pública de parte del ejecutivo que dicta medidas legislativas (gubernativas pero legislativas), de delimitación de este servicio público, para defender los derechos del consumidor, del usuario, del ciudadano que también tiene derechos fundamentales que proteger.

La Constitución no aclara el sentido del contenido esencial del derecho. El artículo 28.2 permite algunas deducciones lógicas: «Se reconoce el derecho a la huelga de los trabajadores para la defensa de sus intereses». Aquí se puede observar que el derecho «a la huelga» es un derecho finalista, de defensa de los intereses de los trabajadores. De ahí que se puedan considerar ilegales las huelgas de solidaridad y sobre todo las llamadas huelgas politicas.

La doctrina ha tratado el tema del contenido esencial de los derechos, como si en realidad los derechos fueran algo mensurable en sí mismos, susceptibles de un cuantum, sobre los que el "contenido esencial" constituye el núcleo ontológico mínimo, inatacable por el legislador.

Por el contrario, lo que la experiencia demuestra, incluidas las propias resoluciones judiciales, es que se trata de conceptos mutables al socaire de ciertas conceptuaciones previas, y desde luego no determinables, de una vez por todas, ni en el tiempo ni en el espacio. Si no lo son en sí mismos los derechos fundamentales en cuanto tales, difícilmente podrán los derechos ser determinados en cuanto a un contenido esencial. Lo más razonable es que el contenido esencial de los derechos fundamentales se vaya ampliando conforme lo haga, a su vez, el desarrollo progresivo de la CE.

Pero con independencia de esta primera parte del párrafo $2 .^{\circ}$ del artículo 28 de la CE, el último inciso sí que representa la ponderación misma del derecho, cuando mandata a la ley futura, a establecer las garantías precisas para «asegurar el mantenimiento de los servicios esenciales de la comunidad». Junto al contenido esencial del derecho "a la huelga", hay un contenido esencial a los "servicios de la comunidad", que parecen representar el límite del derecho a la huelga.

Pero no todos los servicios se prestan de forma esencial, o por decirlo mejor, hay una graduación entre los diferentes servicios que se pres$\tan$ a la sociedad. Luego, hay que determinar entonces la exigencia de cuáles son servicios esenciales y cuáles no, en orden a delimitar el contenido esencial del derecho a la huelga. En primer lugar, los derechos 
fundamentales representan un limite. Asi lo ha establecido el TC. Pero ¿que derechos fundamentales, los especialmente protegidos como es el caso de la misma huelga, o todos los derechos fundamentales? Porque la propiedad privada es un derecho fundamental, especialmente lesionado en el caso de la huelga, no sólo en lo que se refiere a la cesación momentánea de la explotación, sino a los eventuales daños que puedan ocasionar los huelguistas en el ejercicio legitimo de su derecho constitucional. ¿Es en este caso la lesión de la propiedad privada un límite oponible con igualdad de rango, al derecho especialmente protegido, respecto de otro no sujeto a estas garantias? ¿Lo es respecto del ejercicio violento del derecho, con daños materiales intencionalmente producidos para extender el conflicto? En tal caso se están oponiendo en la ponderación derechos no parangonables, que sí lo serían, por ejemplo, el artículo 15 de la CE (integridad física y moral), o el artículo 17 acerca de los piquetes en lo que se refiere a la eventual restricción de la libertad de información.

¿Debe operar el criterio de racionalidad cuando un sector de una empresa enclavado de forma fundamental en la producción de la empresa realiza huelgas que paralizan a los demás trabajadores de ésta y que lesionan el derecho al trabajo, establecido en el artículo 35 de la CE como derecho no especialmente protegido?

Este planteamiento de las cosas se complica aún más con el carácter que adoptan ciertas formulaciones sociales, que hasta hace relativamente poco tiempo se concebian como actividades de ocio (vacaciones), y que progresivamente van siendo reconocidos socialmente como derechos en el marco de la salud. Ciertamente, el carácter de servicio público ha cambiado. Hasta ahora, el servicio público era aquel que se prestaba en la actividad pública, estatal. Ahora el servicio público puede ser cualquier servicio que afecte a la comunidad. No siendo el suministro de artículos de primera necesidad śervicio público, puede ocurrir que en una huelga prolongada los artículos de primera necesidad cuya gestión se realiza por la economia privada, adquiera carácter de servicio público.

\section{EL CONTENIDO ESENCIAL DEL DERECHO DE HUELGA}

\section{Determinación de lo que es el contenido esencial de los Derechos Fundamentales}

El contenido esencial de los derechos fundamentales ha sido tratado por la doctrina alemana a propósito de los Derechos Fundamentales, como 
un núcleo esencial que caracterizará a todo derecho fundamental, sin el cual este derecho estaría despojado de su sentido. Por decirlo de alguna forma, el contenido esencial viene a ser la característica peculiar de cada derecho, sin la cual el derecho pierde su sentido. STEIN recoge las dos teorías acerca del contenido esencial contempladas en la doctrina alemana: la teoría llamada absoluta, según la cual el contenido esencial es para cada derecho delimitable con independencia de la colisión de intereses en cada caso concreto, y la teoría relativa, que pone en relación el contenido esencial con los valores e intereses que concurren en cada caso concreto 1.

Por su parte, I. DE OTTO ha referido la influencia de la Ley Fundamental una vez más en nuestro texto constitucional, en lo que se refiere al artículo 53 en relación con el artículo 19 de la Ley de Fundamental. La defectuosa redacción, sin embargo, del artículo 53 es la que lleva a confusión al legislador y al TC en cuanto al respeto a ese contenido esencial, pues si bien en la regulación alemana queda claro que el legislador está limitado en la regulación de los Derechos Fundamentales, la redacción del artículo 53 hace pensar en una habilitación para limitar el contenido del derecho por el legislador ${ }^{2}$.

Esta puede ser una razón, aunque no la única, de que la determinación del contenido esencial de los derechos en nuestro ordenamiento y en la jurisprudencia haya adoptado formalmente la teoría absoluta de los contenidos esenciales, pero en la práctica estamos ante el desarrollo de la teoría relativa. Es verdad que el "contenido esencial» se supone conforme a la idea expuesta por I. DE OTTO de círculos concéntricos, en los que hay un núcleo esencial mínimo inatacable por el legislador ${ }^{3}$. Pero esta formulación en la práctica no viene a ser muy diferente de la teoría relativa, puesto que el TC va a valorar el contenido esencial de la huelga conforme a la teoría de la ponderación de valores, en donde el núcleo mínimo no tiene un contenido preciso. En la misma sentencia 11/81, el TC aclara que el derecho a la huelga no es absoluto, en relación con las formas abusivas de huelga.

La relativización del contenido esencial es razonable desde la posición de que no pueden existir derechos absolutos. Pero plantea de inmediato el problema de cuáles son los mínimos inatacables por el legis-

\footnotetext{
StEIn: Derecho político, Ed. Aguilar, Madrid 1973, p. 247.

I. DE OTTO: "La regulación del ejercicio de los derechos y libertades", en Derechos fundamentales y Constitución, Civitas, Madrid 1988, p. 107.

3 Ibidem, p. 131. «El contenido esencial es un núcleo duro, un kern o un wesenskern absolutamente resistente a la acción limitativa del legislador. Para expresar la misma idea en términos espaciales se dice que en el interior del núcleo se dibuja un círculo concéntrico cuya circunferencia es la frontera que el legislador no puede traspasar en ningún caso, ni siquiera cuando el límite pudiera venir justificado por la protección de otro derecho o de otro bien de rango constitucional»"
} 
lador o por la Administración, sin los cuales el Derecho Fundamental es ilusorio. Dicho de otra forma, la delimitación del contenido esencial parece apuntar a un criterio histórico espacial, el aquí y el ahora, sobre los cuales se formulan posiciones de transitoria vigencia. $Y$ junto al criterio de vigencia, la casuística del caso concreto. De este modo, el contenido esencial del derecho a la propiedad que ahora se define puede no servir necesariamente para después, dependiendo este ahora y este después de varios criterios de determinación.

Donde la idea de contenido esencial en la doctrina del TC adquiere cuerpo de doctrina es, además de la sentencia 11/81, de 8 de abril, en la sentencia 37/87, de 26 de marzo, que resuelve el Recurso de inconstitucionalidad contra determinados artículos de la Ley del Parlamento de Andalucía 8/1984, de Reforma Agraria. Aqui, el concepto que mantiene el TC de lo qué es el contenido esencial, no varia de forma sustancial en una y otra Resolución. En el primer caso, es contenido esencial del derecho de un derecho fundamental «aquella facultad o posibilidad de actuación necesaria para que el derecho sea reconocible". En el caso de la sentencia 37/87 sigue siendo contenido esencial «aquella parte del contenido del derecho que es absolutamente necesaria para que los intereses juridicamente protegibles, que dan vida al derecho, resulten real, concreta y efectivamente protegidos». El propio TC basa su criterio actual de contenido esencial en el anterior FJ núm. 10 de la sentencia 11/81. En estos seis años, el TC ha tenido que matizar muy precisamente el contenido esencial del derecho a la propiedad privada en relación con el interés social, en la sentencia 111/ 83, por la que se desestima la inconstitucionalidad del Real Decreto-Ley que sirvió a la expropiación del grupo de empresas de Rumasa. Pero hay un criterio inalterable en el TC en torno al concepto de contenido esencial y es la idea de que cada derecho fundamental posee en sí mismo un núcleo minimo de protección sin el que no cabe hablar de este derecho. Pero dicho esto, muy poco más se puede establecer respecto de este mínimo. Porque ¿representa este mínimo un tope para el legislador, o más bien, debe ser el punto de partida inicial de un derecho cuya extensión como derecho subjetivo llegue hasta donde los demás Derechos Fundamentales operen a su vez como límite? Acerca de esto, lo que el TC ha dicho es más bien lo primero, es decir, que por debajo del contenido esencial no hay Derechos Fundamentales, y que éste es, por tanto, el limite y no precisamente el punto inicial o de partida.

Esta posición que la jurisprudencia viene definiendo acerca del contenido esencial puede hacer ilusorios ciertos derechos fundamentales, pues determinado el contenido esencial del derecho a la huelga, como la cesación de la actividad laboral, para ejercitar una presión conducente a mejorar el contrato de trabajo, unos servicios mínimos que operen restrictivamente, afectan al contenido esencial.

Recapitulando se puede decir que el contenido esencial gira en torno a estas consideraciones: 
a) No es un criterio atemporal, sino que la misma idea de contenido esencial puede parecer diferente en un momento histórico que en otros. Piénsese cómo la limitación del derecho a la vida, en colisión con la dignidad de la madre en los supuestos de violación, la justifica el TC conforme criterios de ponderación de derechos, afectando, sin embargo, al contenido esencial del derecho a la vida, que es definido por el propio TC como «un prius lógico y ontológico".

b) Es un criterio casuístico, en cuanto que no se define ni delimita más que en cada caso concreto.

c) Es un criterio relacional, puesto que el contenido esencial atiende a la ponderación de derechos. En este sentido hay que plantearse, asimismo, qué derechos son equiparables entre sí, cabiendo las siguientes reflexiones en torno a esto:

Entre los Derechos Fundamentales especialmente protegidos, la colisión ha de ponderarse en función de cada contenido esencial. Y llegado el caso de que la colisión entre ambos afecte a los contenidos esenciales de estos derechos, el TC no tendrá otra salida más que la de atender a una solución enmarcada en la teoría «relativa». Cuando se colisione un Derecho Fundamental especialmente protegido con otro Derecho Fundamental no especialmente protegido (el derecho de huelga con el derecho a la propiedad privada), la ponderación se tiene que hacer prevaleciendo el Derecho Fundamental especialmente protegido (caso Sorolla, que no se resolvió precisamente conforme a estos criterios). Y por último, Derecho Fundamental con otros bienes y valores constitucionales, que deberá solventarse lógicamente a favor de los primeros. Con ello no se hace más que seguir la jerarquización establecida por el constituyente.

EI TC ha venido hasta ahora haciendo compatible el derecho a la huelga con los bienes constitucionalmente protegidos. Esta ponderación es correcta siempre que se efectúe teniendo en cuenta las categorías descritas, dando a cada Derecho Fundamental el valor que el constituyente ha dado en el texto constitucional ${ }^{4}$.

4 I. DE OTTO no ve correcta la teoría de la ponderación en este caso, sino que hay que acudir a la interpretación de las normas constitucionales, pp. 135 y 144 de op. cit. 


\section{El contenido esencial del derecho a la huelga en la jurisprudencia del TC}

Como se ha visto, el artículo 53 al hablar del contenido esencial to hace con referencia a los límites legislativos impuestos: que la norma sea de rango legal y que respete este contenido. Pero si se admite un contenido esencial en un derecho, éste no sólo ha de operar como mínimo en la regulación legal, sino en todos los ámbitos en que este derecho cobre vida. Por ello, en lo que se refiere al derecho a la huelga, el hecho de que no exista ni se prevea en algún tiempo regulación legal, no significa que no se produzcan actuaciones respecto del derecho, algunas de ellas eventualmente delimitadoras de su contenido esencial. No es otra cosa lo que ocurre cuando la Administración determina servicios mínimos a fin de asegurar la prestación de servicios a la comunidad. Esta actuación de la Administración constituye una limitación del derecho, que rozará o respetará su contenido esencial según en la forma en que el Estado determine estos servicios. Recordemos que el derecho de huelga en nuestro país se asienta sobre una legislación preconstitucional (RDL 17/77, de 4 de marzo, de relaciones de trabajo), un reconocimiento constitucional (art. 28) y una sentencia del TC que sentó ciertos criterios acerca de todas las cuestiones relacionadas con la constitucionalidad de la huelga en su regulación por el Decreto (St. 11/81, de 8 de abril).

En la sentencia de 8 de abril de 1981, el Tribunal Constitucional ha revisado de alguna forma la idea de la huelga desde el punto de vista de como se crea en la CE. Y quizá sobre todo del Derecho positivo que conformaba la huelga en nuestro ordenamiento, desde el punto de vista del Decreto 17/77, de 4 de marzo, de relaciones de trabajo, con una regulación preconstitucional. La trascendencia de la doctrina del TC acerca del derecho a la huelga está además en que previsiblemente, todavia durante bastante tiempo, el TC deba seguir interpretando los preceptos preconstitucionales y completando algunas lagunas legales (servicios mínimos, calificación de legalidad o ilegalidad), porque no hay una situación de los agentes sociales tendente a favorecer un consenso social respecto de la regulación del ejercicio de la huelga. Más bien al contrario, hay una crispación social evidente en todas estas materias que puedan eventualmente recortar derechos que en principio se vislumbran y se diseñan en la Constitución con la mayor amplitud, y que, por lo tanto; de alguna forma ha de entenderse que cualquier ley lo que haría es recortarlas.

La sentencia 11/81, de 8 de abril, del Tribunal Constitucional, por la que se estima en parte el recurso de constitucionalidad contra el DecretoLey $11 / 77$, de 4 de marzo, sobre relaciones de trabajo, en relación con los preceptos sobre la huelga legal, establece unos criterios en el Tribunal Constitucional que van a ser la base de las sentencias posteriores. 
Hay un antecedente jurisprudencial sobre el que merece la pena detenerse brevemente. Ya en fecha 23 de noviembre de 1979, el TCT habia dictado una sentencia por la que estimaba como improcedentes unos despidos realizados por la empresa a consecuencia de una supuesta huelga ilegal, y había roto con el requisito legal de la exigencia de la declaración de la huelga por cada centro de trabajo, por lo que ahora el TC arranca ya de este pronunciamiento. Dice el TCT en su sentencia que «no puede obstaculizar el carácter legal de una huelga de sector o de ámbito territorial amplio el que el acuerdo no haya sido adoptado uno por uno por todos los centros de trabajo afectados, cuando se hiciera por los sindicatos más representativos en el ámbito del convenio colectivo en deliberación". Y consecuentemente estima la improcedencia de los despidos producidos al amparo de esa visión restrictiva del derecho a la huelga.

En esta situación se produce el recurso de inconstitucionalidad contra el Decreto-Ley regulador de la huelga. EI TC establece varios criterios de base:

1. Que no es necesario el acuerdo por centros, salvo que la huelga se refiera a un solo centro de trabajo.

2. Que el empresario no tiene el monopolio del nombramiento de los servicios de mantenimiento imprescindibles.

3. Que existe constitucionalmente la posibilidad de un arbitraje obligatorio, siempre que sea imparcial.

4. Que no es inconstitucional el nombramiento de servicios mínimos.

5. Que son legales las huelgas de solidaridad, aunque el interés profesional no sea directo.

6. Que son inconstitucionales los laudos de obligado cumplimiento en materia de conflictos colectivos, lo que queda ahora mismo fuera de nuestra consideración, porque nos estamos refiriendo exclusivamente a la huelga.

En esta sentencia el TC alude ya al contenido esencial del derecho. Pero es en la sentencia 120/83 por la que se desestima el recurso de amparo solicitado por los trabajadores del Liceo Soroya, que hicieron una serie de manifestaciones entendidas por la empresa como calificativas de una transgresión de la buena fe contractual, durante el ejercicio del derecho de huelga, cuando se plantea de una manera indirecta, pero efectiva, el límite de este contenido esencial. 
El Estado debe respetar el contenido esencial del derecho de huelga. $Y$ el empresario, ¿está o no vinculado por el contenido esencial del derecho? En la sentencia que origina este recurso de amparo, el TC valora si las manifestaciones de los trabajadores del centro estaban o no dentro de los límites del derecho de la libertad de expresión.

Pero el TC no entra en la ponderación entre el derecho de la empresa a asegurar su continuación como empresa, y el de los trabajadores en asegurar su salario. Ni siquiera entra a considerar si el empresario respetó el contenido esencial al derecho de los trabajadores a proclamarse en huelga, si fue o no violado en cuanto se contrataron otros profesores para realizar las funciones que los huelguistas no iban a realizar. ¿No se puede decir que la empresa violó el contenido esencial del Derecho Fundamental a la huelga?

Llama la atención el hecho de que el TC mantenga la exigencia de la buena fe del artículo 7 del Código Civil para los huelguistas, y sin embargo no la mantenga para la empresa que contrata trabajadores con clara violación del contenido esencial.

$Y$ valora de esta forma el Tribunal, que pese a que el Real DecretoLey prohíbe la contratación de trabajadores que no estuviesen vinculados a la empresa al tiempo del anuncio de la huelga, no justifica esa conducta la que los trabajadores tuvieron ${ }^{5}$.

La conclusión de todo esto èn el fundamento jurídico cuarto es que el despido se califica correctamente como procedente por los jueces ordinarios al haber ponderado la extralimitación en la libertad de expresión, y sin que la conducta claramente violadora del contenido esencial del derecho a la huelga se considere más que la infracción del Decreto que no justifica la actuación de los trabajadores.

\section{EL CONTENIDO ESENCIAL EN EL DERECHO A LA HUELGA Y LOS SERVICIOS ESENCIALES DE LA COMUNIDAD}

En todos los derechos fundamentales, prácticamente hay una colisión entre ellos: el derecho a la vida con el de la dignidad de la mujer, el derecho a la libertad de expresión con el honor, el derecho a la huelga con

5 Acerca de la buena fe como elemento de colisión en la ponderación de los Derechos Fundamentales, ver I. DE Отто, op. cit., p. 113. 
el derecho a la propiedad. En tal caso, la ponderación se expresa desde el punto de vista de los servicios mínimos.

Ahora bien, visto que la huelga puede colisionar con otros Derechos Fundamentales, o con otros derechos no fundamentales, es necesario que a la hora de efectuar la ponderación, el TC tenga en cuenta el derecho que colisiona con la huelga y su naturaleza en cuanto a protección y rango.

El ejercicio del derecho a la huelga tiene fijado un límite por la misma Constitución, en cuanto han de quedar garantizados los servicios esenciales de una comunidad. Estos servicios esenciales han sido ya determinados por el TC en la sentencia 26/81, de 17 de julio, que define lo que son los servicios esenciales. «Un servicio no es esencial tanto por la naturaleza de la actividad que se despliega como por el resultado que con dicha actividad se pretende. Más concretamente por la naturaleza de los intereses a cuya satisfacción la prestación se endereza. Para que el servicio sea esencial deben ser esenciales los bienes e intereses satisfechos." Los derechos fundamentales, las libertades públicas y los bienes constitucionales protegidos.

En esto el TC no se aparta de los criterios de la proporcionalidad, e incluso de la racionalidad, conforme a la ponderación de otros derechos fundamentales.

Pero aquí es donde aparece el problema fundamental del derecho a la huelga en cuanto a su contenido esencial. El contenido esencial del derecho a la huelga es, según el propio TC, «la cesación efectiva del trabajo". Luego todo lo que dificulte esta cesación, está afectando al contenido esencial. Los servicios mínimos establecidos, en cuanto que satisfacen la colisión de un Derecho Fundamental especialmente protegido con otro también especialmente protegido, están justificados en función de la teoria de la ponderación. Pero no lo están en cuanto desborden estos Derechos Fundamentales especialmente protegidos. Una ojeada a las resoluciones judiciales nos dirá si hay o no un respeto al contenido esencial del derecho a la huelga. En tanto en cuanto en éstas se ponen de manifiesto los servicios minimos establecidos por la autoridad administrativa y su grado de confirmación por los jueces.

Ya M. T. FREIXES ha puesto de relieve la diferente posición de los órganos jurisdiccionales en relación con el TC en el tema de los servicios esenciales ${ }^{6}$.

En efecto, hay varios conceptos equivocos en el DRLRT y el texto constitucional, que semánticamente se hace necesario delimitar. La Constitución dice taxativamente «mantenimiento de servicios esenciales». Por to tanto, el mantenimiento implica que durante el periodo que dure la huelga

- M. T. FReIXES SANJUÁN: «La huelga y sus garantías constitucionales», en $R D P$, núm. 22, 1986, pp. 228 y ss. 
los servicios esenciales no sean suprimidos, evitando situaciones irreparables (urgencias clínicas, transportes colectivos, etc.).

Por su parte, el DRLRT dice en su artículo 10 que «cuando la huelga se declare en empresas encargadas de la prestación de cualquier género de servicios públicos o de reconocida e inaplazable necesidad, y concurran circunstancias de especial gravedad, la autoridad gubernativa podrá acordar las medidas necesarias para asegurar el «funcionamiento» de los servicios. Este párrafo segundo del artículo 10 ha sido interpretado en la sentencia 11/81, del TC, en el sentido de que tales medidas serian de «mantenimiento", con lo cual se cambia el sentido del artículo 10 de forma que los servicios no podrán tener un funcionamiento tendente a la normalidad, sino que deberán exclusivamente mantener el servicio. Lo que es cualitativamente distinto, pues la idea de funcionamiento implica una cesación de la huelga en pro de otras razones de interés social. La idea de mantenimiento es la de evitar el deterioro del servicio o la de acudir a atender a una urgencia, no la de reanudación del servicio a que apuntaba la interpretación original de “funcionamiento".

La interpretación de la Administración hay que entender que sigue muy cercana a la idea de que los servicios públicos están por encima del derecho a la huelga, de modo que ésta operase sólo en la iniciativa privada y en sectores que no sean de servicio público. No de otro modo se entiende que los servicios mínimos hayan sido señalados a veces con el 100 por 100 de la plantilla, en el caso de Juzgados de distrito, hoy extinguidos, y en donde la Administración evidenciaba su propia política judicial deficitaria ?

Otras veces siendo el porcentaje del 58,8 por 100 del personal, se cumple el 75 por 100 de las expediciones horarias, llegando a veces al 100 por 100 (St. del TS de 14/5/82, R.A. 3901, por la que se revoca la resolución administrativa fijando los servicios mínimos).

Pero los órganos jurisdiccionales a veces han confirmado servicios minimos en materia de transportes que desnaturalizan por completo el derecho a la huelga, pues no es razonable pensar que vaya a tener efectividad una huelga en la que se señale el 80 por 100 de los servicios en horas punta de producción, porque en esta situación, confirmada por el TS en sentencia $26 / 1 / 85$, R.A. 268 , la justificación de esta medida no puede, razonablemente, atender al ejercicio del derecho de huelga, sino que hay una subordinación de este derecho fundamental especialmente protegido a otro derecho de recibir servicios de transporte de los poderes públicos que no tiene el mismo relieve constitucional.

Hay otro argumento que relativiza completamente el contenido esencial del derecho y es el caso de cuando los servicios minimos se prestan

> M. T. Freixes, op. cit., pp. 230 y ss. 
sin tener en cuenta la oferta de otras empresas. El caso es que el TC ha venido definiendo conceptos relativos (duración de la huelga, sector afectado, etc.), pero sin embargo cuando llega el momento de definir los servicios mínimos se ha ignorado una realidad, que es la de la oferta de servicios alternativos con los que cuentan los usuarios. El argumento es que estos otros sectores también pueden eventualmente ejercitar el derecho a la huelga, pero este argumento cae de su peso, pues una huelga concurrente permitiría a la autoridad incrementar los servicios esenciales, a la vista de las nuevas circunstancias. Por tanto, este carácter restrictivo opera por sí mismo, sin mayor justificación.

Y hasta el punto de señalar la Administración el mismo número de trabajadores para la realización de un servicio de mantenimiento que en los servicios ordinarios (St. del TS de 28/9/82, R.A. 6.303).

Una última cuestión hace referencia a la poca efectividad de las sentencias acerca de servicios mínimos, pues aunque la doctrina no deja lugar a dudas del proceso preferente y sumario del derecho de huelga ${ }^{8}$, la misma realidad procesal hace inviable que la decisión jurisdiccional acerca de los servicios mínimos haga posible una resolución judicial ejecutable con anterioridad al ejercicio del derecho a la huelga, dándose la curiosa circunstancia de que esta resolución judicial se produzca años después de haber ejercitado el derecho.

Para ello no habría más solución procesal que la suspensión de la resolución administrativa acerca de los servicios mínimos, pues al ser los actos dictados por la Administración ejecutables con independencia de los recursos que contra ellos se formulen, en la práctica no hay posibilidad de suspender los efectos con lo que ésta juega con la ventaja que le proporciona la inevitabilidad del acatamiento de estos servicios mínimos, y la práctica obsolescencia de una sentencia posterior inejecutable por extemporánea.

Con eso se pone en cuestión el problema de la verdadera dimensión del contenido esencial del derecho a la huelga, y de la justificación de la teoria de la autorregulación.

Son conocidas las tres posiciones doctrinales acerca de la regulación de la huelga en nuestro ordenamiento. Desde las posiciones que consideran que debe haber una ley reguladora del derecho (pertenecientes por lo común a sectores empresariales fundamentalmente), a las que consideran que cualquier ley coartaría el contenido esencial del derecho (de general consenso en las organizaciones sindicales), hasta las que estiman

a Sobre las posiciones doctrinales en el tema de autorregulación, ver E. Rojo TORRECILLA: «Balance de diez años de desarrollo del derecho constitucional de huelga y perspectivas de futuro», en $R E P$, núm. 66, 1989. 
necesaria la fórmula mixta de autorregulación con control administrativo y judicial ${ }^{9}$.

La defensa de la autorregulación pura parte de la base de que hay que considerar a los sindicatos como organizaciones semipúblicas, encaminadas a la defensa de los derechos de los trabajadores pero que están enmarcadas en los intereses generales del país exactamente igual que otras instituciones ${ }^{10}$. Por esto, el desarrollo de una huelga supone para el sindicato, igual que el ejercicio de cualquier otro derecho constitucional, el de reunión o manifestación, la estructura precisa de mantenimiento de un orden social que evite situaciones extremas. Los que temen que la autorregulación sea un caos recuerdan posiciones de tutela administrativa discutibles en un Estado de Derecho en donde cada uno de los agentes sociales ha de ser responsable ante la opinión pública de sus actuaciones. Las organizaciones sindicales no han demostrado no serlo, y en igualdad a otras instituciones públicas. Por lo tanto, estas afirmaciones quedan en el campo de lo meramente opinable ${ }^{11}$.

Por otra parte, el sistema de autorregulación mixta de que parte DURÁN LÓPEZ como inevitable por mandato de la sentencia del TC 11/81, no es exactamente asi ${ }^{12}$. Recordemos que la sentencia habla de la autorregulación en condiciones de solvencia moral de los huelguistas y de madurez del sindicato, por to que esta autorregulación no tiene que venir establecida necesariamente por ninguna ley. En el mismo momento en que se derogase el RDLRT estaríamos ante una autorregulación, determinada simplemente por ausencia de norma reguladora, que dejaría al artículo 28.2 como única norma reguladora de rango constitucional.

La corrección de las eventuales irregularidades de los huelguistas tiene conocido marco en el Derecho Penal. Y las que no fuesen delictivas

9 F. DURAN LOPEZ: «Los derechos sindicales y la regulación de la huelga», $R E D T, 1989$. En la p. 383 afirma que cla autorregulación implica la aceptación de una serie de valores y de compromisos de comportamiento por parte de las organizaciones sindicales que no se da todavia entre nosotros; y la autorregulación exige la existencia de algunas condiciones técnicas que permitan su actuación en el marco de una determinada ordenación jurídica de las relaciones laborales, que tampoco concurren hoy por hoy entre nosotros». Es curioso que precisamente las organizaciones sindicales que han dado muestras de madurez política y contención salarial en todo el proceso de la transición política, se consideren por algún sector de la doctrina como instituciones a tutelar para evitar que su supuesta irresponsabilidad pueda originar perjuicios sociales irreparables.

${ }_{10}$ Ibidem, p. 384.

11 La posición del TC es razonable en cuanto al tiempo de espera necesario en 1981, para que las instituciones sindicales se pudiesen consolidar. No olvidemos que a esta fecha estaban todavia en un proceso de consolidación, tanto las centrales sindicales como las organizaciones empresariales.

12 DURAN LOPEZ, op. cit., p. 386. 
con una sanción administrativa o al Comité de Empresa convocante, exactamente igual que ocurre con la potestad sancionadora de la Administración en materia laboral. Por último, habría una responsabilidad civil subsidiaria conforme a lo establecido en el Código Civil, con lo que el cuadro legislativo quedaba perfectamente configurado.

El artículo 496 del Código Penal castiga a los que obliguen a otras personas a iniciar o continuar una huelga. De modo que hay norma positiva capaz de evitar los excesos en la huelga, como los demás artículos del Código Penal que castigan como reos de culpa a los que producen daños a personas o cosas.

El artículo 1902 del Código Civil, por el que se salva la responsabilidad civil en caso de daños. Y en general nuestro ordenamiento jurídico tiene sobrada capacidad para hacer frente a la autorregulación, sin tener que crear una nueva ley.

Menor atención merece aún la idea de que para la autorregulación es necesaria previamente la unidad sindical. En la base de esta idea está, una vez más, la creencia en una sociedad lo menos pluralista posible, como si lo plural y lo democrático se contradijeran, cuando la realidad es justamente lo contrario.

\section{CONCLUSIONES}

Primera. El hecho de que el TC declarara compatible el Real Decreto-Ley 17/77, de 4 de marzo, con el reconocimiento constitucional del derecho a la huelga del artículo 28 , aunque de alguna manera lo modificara, nos hace estar hoy funcionando con unos esquemas preconstitucionales, con todo lo relativo que esto pueda ser, pero desde luego la legislación no tiene el señuelo constitucional, porque es una interpretación postconstitucional de una norma preconstitucional.

Segunda. EI TC mantiene un concepto de huelga que hay que seguir situando en el ámbito de una legislación. No es partidario de la autorregulación en un plazo razonablemente establecido conforme a la consolidación de las organizaciones sindicales. Entiende el derecho de huelga como derecho individual, cuyo contenido esencial es la cesación en el trabajo.

Tercera. El derecho a la huelga, en tanto que Derecho Fundamental, solamente debía tener como límite el de los demás Derechos Fun- 
damentales. Sin embargo, la ponderación de derechos que efectúa el TC se realiza conforme a «bienes y derechos jurídicamente protegidos", si bien el rango que tienen unos y otros hace que la ponderación se efectúe teniendo en cuanta este diferente nivel. Lo que se refleja en el contenido esencial del derecho de forma tal que siendo el contenido esencial del derecho a la huelga la cesación del trabajo, este mínimo se convierte en el máximo del derecho que queda mediatizado por los servicios esenciales de la comunidad.

Cuarta. Como en otros casos, y pese a tratarse en éste de un derecho con contornos sociales muy precisos que podría justificar lo contrario, no estamos en el caso de elaboración jurisprudencial propia por parte de jueces ordinarios, sino, una vez más, de categorias importadas del TC. 


\section{BIBLIOGRAFÍA}

Alonso GaRcla, Manuel, y otros: La huelga y el cierre empresarial, Instituto de Estudios Económicos, Madrid 1979.

BAÑo LEÓN, J. M.: «La distinción entre derecho fundamental'y garantía institucional en la CE», REDC, n. ${ }^{\circ} 24,1988$.

Baylos Grau, Antonio: Derecho de huelga y servicios esenciales, Edit. Tecnos, Madrid 1987.

Baylos, Antonio, y TERRADILlos, Juan: "Controles institucionales al ejercicio del derecho de huelga", en REDTr., Madrid 1989.

CRUZ VILLALON, P.: "El legislador de los derechos fundamentales", Ponencia presentada a las VIII Jornadas de Derecho Constitucional Comparado, Madrid 1989.

DURÁN LÓPEZ, F.: «LOS derechos sindicales y la regulación de la huelga", REDTr., Madrid 1989.

FReixes SANJUÁN, T.: «La huelga y sus garantías constitucionales», RDP, $\mathrm{n} .{ }^{\circ}$ 22, 1986.

Gárate Castro, F. J.: "Modalidades de huelga en el ordenamiento jurídico español. La huelga intermitente", REDTr., $\mathrm{n}^{\circ} 25$.

GARCIA BLASCo, Juan: El derecho de huelga en España: Calificación y efectos juridicos, Ed. Bosch, Barcelona 1984.

Garcia-Perrote Escartín, Ignacio: La huelga con ocupación del lugar de trabajo, Ed. Akal, Madrid 1981. 
Martín Retortillo-Otto y Pardo: Derechos fundamentales y Constitución, Ed. Civitas, Madrid 1988.

MARTIN VAlverde, A.: "Los límites del derecho de huelga en la Administración Pública», REDC, n. ${ }^{\circ} 18,1986$.

Palomeque López, Manuel Carlos: «La regulación por ley del derecho de huelga», en Documentación Laboral, n. ${ }^{\circ} 23,1987$.

RoJo TORRECILLA, Eduardo: «Balance de diez años de desarrollo del derecho constitucional de huelga y perspectivas de futuro", en $R E P, \mathrm{n} .^{\circ} 66$, 1989.

RUIz Pontones, Manuel: «La huelga en la jurisprudencia del Tribunal Supremo y Tribunal Central de Trabajo", en Documentación Laboral, n. ${ }^{\circ} 24,1988$.

Serrano Carvajal, José: "Manifestaciones recientes sobre el derecho de huelga en España», en Documentación Laboral, n. ${ }^{\circ} 22,1987$.

Stein, E.: Derecho Politico, Biblioteca Jurídica Aguilar, Madrid 1973.

VV. AA.: Huelga, cierre patronal y conflictos colectivos, Editorial Civitas, Madrid 1982. 